FANI AlEZRA

Studies of Izrael

\title{
EDUCATIONAL INITIATIVES \\ AS A WAY FOR THE EMPOWERMENT OF THE PRESCHOOL TEACHER AND THE IMPROVEMENT OF HER IMAGE
}

\begin{abstract}
Alezra Fani, Educational Initiatives as a Way for the Empowerment of the Preschool Teacher and the Improvement of Her Image [Inicjatywy edukacyjne jako sposób zatrudnienia nauczyciela przedszkolnego i wzmocnienie jego wizerunku]. Studia Edukacyjne nr 53, 2019, Poznań 2019, pp. 393-405. Adam Mickiewicz University Press. ISSN 1233-6688. DOI: 10.14746/se.2019.53.22
\end{abstract}

The recognition of the importance of early childhood education is steadily increasing. Many reports published in Israel and around the world address the tremendous and critical impact of this age on the individual and on society. In contrast, the professional image of the preschool teacher in Israel is low, as in many countries. The professional image influences the choice of the teaching profession and the acceptance conditions in the teacher training colleges. This article addresses unique educational pedagogical initiatives that incorporate advanced technology and innovative teaching methods that may have positive influence on the preschool teacher's image and serve as a focus for community involvement, positive advertising, and empowerment of the children and the preschool. Therefore, the aim of the article is to emphasize the importance of the educational initiatives and their direct and indirect impact on the preschool image and the parents' satisfaction with the preschool activity, to encourage the preschool teachers who do not yet integrate educational initiatives in their activity to do so, and to emphasize the importance of the involvement of the parents and the community in the preschool pedagogical activity. This research was performed through the distribution of questionnaires to the parents in the preschools where educational initiatives were held and in the preschools where these initiatives were not held and the examination of the parents' satisfaction.

Key words: educational initiatives, preschool teachers image, parents satisfaction, pedagogical activity

\section{Introduction}

The recognition of early childhood education importance is increasing. Many reports have been published in Israel and around the world describing the situation of education in early childhood. In Israel, the Trachtenberg Report ${ }^{1}$

\footnotetext{
${ }^{1}$ M. Trachtenberg, Report of the Committee for Social Economic Change, Jerusalem 2011, p. 107.
} 
determined that: "Children are the foundation stone of every healthy society that wants to continue to exist". The report relies upon many international research studies on the topic of early childhood education, when their findings clarify that educational lacks at a young age harm significantly the child's development and ability to advance at a later age.

However, there is a tremendous gap between the importance and necessity of the preschool ${ }^{2}$ teacher's role and the image of the profession of the preschool teacher in society. The preschool teacher's work is perceived as something that "everybody can do" and the value of the profession is inferior relative to its importance. The professional image influences the choice of the teaching profession and the conditions of acceptance to the training colleges. There is increasing need to improve the image, and the engagement in the image of the preschool teacher in the research is sparse, with the exception of a new study ${ }^{3}$ published recently, in which the researchers strengthen the gap existing between the importance of the profession of the preschool teacher and the image in the parents' eyes. The researchers attempt to explain the gap and recommend increased depth of the research in the context of the quality of the preschool teacher's pedagogical-educational work. The engagement in the unique pedagogical-educational work in the preschool leads directly to the "Treasures of the Preschool" and educational academic initiatives, since they can constitute a factor of influence on the preschool teacher's professional image in society and a focus for the involvement of the community and the empowerment of the preschool teacher and the children.

Therefore, the objective of the research study is to increase this awareness and to emphasize the importance of the existence of the educational initiatives and their direct and indirect impact on the preschool teacher's image and on the parents' satisfaction with the activity in the preschool, to encourage the preschool teachers who do not integrate educational initiatives in their activity to do so, and to emphasize the importance of publishing initiatives in the community. In this research study, I chose to examine the contribution of the educational initiatives that exist in the Academia Classroom ${ }^{4}$ program of the Gordon College of Education to the parents' involvement and satisfaction

${ }^{2}$ In Israel the preschool is a framework for children aged three to five,. A preschool may have only one age group. or several age groups. Thus, in this paper when the word preschool is used it refers to an educational framework for children in this age spectrum.

${ }^{3}$ Y. Gilat et al., Perception of Parents regarding the Status and Functioning of the Preschool Teacher, Researchers @ Early Childhood, 5. Levinsky College of Education, 2018.

${ }^{4}$ The "Academia Classroom" Program is an innovative model for the practical training of students. The program has many advantages; one main point is a significant educational initiative led by two students along with the training preschool teacher in each preschool in the cluster (Gordon College of Education Website). 
with the preschool and thus to the improvement of the professional image of the preschool teacher in society. I work in the program as a leading instructor in a cluster of six preschools.

\section{Review of the Literature}

\section{Image of the Profession of the Preschool Teacher in Society}

The committee of experts assembled in the United States with the goal of recruiting high quality personnel for teaching ${ }^{5}$ unequivocally stated that the work conditions, salary, and social image are influential factors: when the level of the salary and work conditions increase, the status of the profession rises, a change is created in the perception of the profession, and it attracts appropriate candidates. ${ }^{6}$ The McKinsey Report ${ }^{7}$ creates a direct relationship between the quality of the teachers, the status of the teachers, and the prestige of the profession: in countries where the profession suffers from a low status it attracts less talented candidates and the status of teaching is lowered.

The situation in Israel is described by Fisherman: ${ }^{8}$ the teacher's status is steadily declining as a result of the shattering of the ideal of the state. There is overwhelming agreement about the complexity of the preschool teacher's role and the difficulties this profession entails. Society recognizes the importance of the profession of educator and its necessity, but its image is low. ${ }^{9}$ Among the researchers there is a difference of opinion about the importance and centrality of the salary and its influence on the image of the teaching profession in contrast to other variables, such as work conditions, perception of the public of the teaching profession, or others who maintain that the teacher herself can influence the image of the profession. ${ }^{10}$ The raising of this topic

${ }^{5}$ M. Cochran-Smith, Constructing Outcomes in Teacher Education: Policy, Practice and Pitfalls, Educational Policy Analysis Archives, 2001, 9(11); L. Darling-Hammond, Teaching for America's Future: National Commissions and Vested Interests in an Almost Profession, Educational Policy, 2000, 14(1).

${ }^{6}$ J.S. Chall, The Academic Challenge: What Really Works in the Classroom? New York 2000.

7 McKinsey Report, How the World's Best-Performing School Systems Come Out on Top, 2007, http://www.mckinsey. com/clientservice/socialsector/resources/pdf/Worlds_School_systems_final.pdf

8 S. Fisherman, Professional Identity and Burnout among Teaching Workers, Haifa 2016.

9 D. Magan, Planning Aspects of Personnel in Teaching and Training for Teaching, Israel 2015.

${ }_{10} \mathrm{~N}$. Blass, Review of the Literature and Description of a Case on the Topic of the Improvement of the Attractiveness of the Teaching Profession. Submitted to the Initiative for Applied Research in Education, Staff of Experts for the Activity "Who Will Teach When Teachers Are Lacking?", Israel 2009. 
into the teachers' awareness will contribute to the sought-for change. Hoyle ${ }^{11}$ maintains that the professional assessment of the teachers is a field depending on teachers and only they can improve it, through display of expertise, control of skills of teaching, and great commitment to the children's success. The preschool teacher's work with parents is very intensive, and she needs the involvement of the parents.

\section{Involvement of the Parents}

The parents' involvement and their satisfaction with the preschool is a topic that expresses a wide range of actions, which pertains to the manner of the parents' organization. Elizur ${ }^{12}$ defines the relationship with the parents through three concepts: involvement, collaboration, and empowerment.

The theoretical basis of this relationship between the educational institution and the home is the very influential ecological-developmental approach of Bronfenbrenner, ${ }^{13}$ in which the environment in which the child was raised has acute influence on his development. It is necessary to address the institution of the family and the educational institution as entwined systems and accept the parents as consumers and partners. The prevalent feeling is there is lack of satisfaction. This feeling is shared by different strata in society. ${ }^{14}$

\section{Educational Learning Initiatives}

The educational learning initiatives express the needs of the individual and the community and give them expression in the way of educational activity that fits into the curriculum. Initiatives express the value-oriented and inclusive outlook of the system of skills and abilities that can be improved through the increase of awareness, training, and experience..$^{15}$ Initiative will contribute to the preschool teacher and to her personal and professional image and is tailored to the learner's needs. It is a skill required as part of the

11 E. Hoyle, Teaching: Prestige, Status, and Esteem, Educational Management \& Administration, 2001, 29(2), p. 139-152.

${ }_{12}$ Y. Elizur, Involvement, Partnership, and Empowerment: A Comparative Model for the Development of a Work Alliance with Families, Conversations: Israeli Journal for Psychotherapy, 1996, 10(2), p. 92-105.

${ }_{13}$ U. Bronfenbrenner, Ecology of the Family as a Context for Human Development: Research Perspectives, Development Psychology, 1986, 22, p. 723-742.

14 N. Ben-Alia, Citizenship of Education in Israel: Deregulation, Democratization, and Increased Responsibility, Jerusalem 2010.

15 A. Peled, Initiative Thinking, Jerusalem 1996. 
skills of the $21^{\text {st }}$ century. According to Pessig, ${ }^{16}$ three main areas of skills are required for a life that is significant for the generation of the future: learning skills, skills of the formation of human relationships, and skills of choice of initiative. A child who develops in an initiative-based environment is witness to and a partner in educational initiatives. Innovative thinking and forging innovative contexts will develop this skill.

Educational initiative is thinking outside of the box, innovative thinking that promotes processes of education for the initiator's wellbeing. ${ }^{17}$ Brand $t^{18}$ maintains that people learn best if the learned material has personal meaning for them, and if they have a certain degree of choice and control. In the development of the initiative, the children are active partners and even lead the development of the initiative and the shaping of the environment the building of the educational environment tailored to the initiative topic.

Recently emphasis is placed on the children's involvement in the building of the environment and the learning processes that involve the children. This approach is called in Israel "the future preschool". In recent years there is increasing awareness of meaningful learning and the importance of the children's participation in the process of their learning. Many educational frameworks emphasize active and experiential learning. ${ }^{19}$ Emphasis is placed on the development of the functioning of self-direction in learning. ${ }^{20}$ The teacher's role changes from learning focused on the teacher to learning directed at the student. ${ }^{21}$ The trends in the Ministry of Education in Israel change and are updated according to international research, which indicates the advantages of the approach that promotes the function of self-direction in learning as one of the main functions in the $21^{\text {st }}$ century.

In addition, the educational initiative enables the branding of the preschool, in an era in which people enjoy the sharing of information on WhatsApp groups, on Facebook, on Instagram, and in different forums where

${ }^{16}$ D. Pessig, Taxonomy of Skills and Future Abilities, [In:] The Contemporary School, From a Complex Existence to a Challenging Future: A Reader, Culture, and Sport, 1997, p. 63-90.

17 R. Aharonov, D. Haviv-Nadan, Education for Initiative, 2015, Retrieved from the website of Department A for Elementary Education, September 10, 2016: http://cms.education.gov.il/ EducationCMS/Units/Yesodi/Hevra/yazamut/Maamar1.htm (Hebrew)

${ }_{18}$ R. Brandt, Powerful Learning, Association for Supervision and Curriculum Development, 1998.

${ }_{19}$ Department of Research and Development, Experiments and Initiatives 2019, Future Oriented Pedagogy. Ministry of Education. Retrieved from the website: http://edu.gov.il/minhalpedagogy/mop/pedagogy-disign/Pages/future-pedagogy.aspx

${ }_{20}$ B.J. Zimmerman, Barry Zimmerman Discusses Self-Regulated Learning Processes, Emerging Research Commentary, 2011.

${ }^{21}$ M. Gibbons, The Self-Directed Learning Handbook: Challenging Adolescent Students to Excel, San Francisco 2002. 
the preschool teachers shared an abundance of ideas and ways of work. Branding is a significant need. The uniqueness differentiates, breaks the routine, creates identity, contributes to the motivation of the children and the staff, and contributes to a sense of belonging and creates pride..$^{22}$ Therefore, the educational initiative contributes greatly, both, to the learner and to the initiator.

The leading of the initiatives and their development in the preschool are the objective in the Academia Classroom program. In the framework of the experience in the program, every pair of students is required to lead an educational initiative. This is an opportunity for them to be a meaningful part of the educational institution, to influence, to attempt complex and innovative activity that will help them develop skills of choice and initiative when they are protected in a network of support. The high point is the presentation day. The process of the construction of the initiative is created in the spirit of active and involved learning ${ }^{23}$ regarding projects and dilemmas and on the basis of initiative-oriented thinking tailored to the unique framework of the preschool and the methods of learning of young children. ${ }^{24}$

The present research study focuses on the image of the preschool teacher in the eyes of the parents and the influence of educational initiatives on this image. The research compares the satisfaction of the parents in the preschools participating in the Academia Classroom program to that of the parents in the preschools not participating in this program. The research study will answer the following questions:

- How is the preschool teacher's image perceived by the parents in preschools where meaningful learning educational initiatives are held?

- How is the preschool teacher's image perceived by the parents in preschools where meaningful learning educational initiatives are not held?

\section{Research Methodology}

The research study was conducted in the quantitative research approach and examined a defined and distinct population.

${ }^{22}$ T. Sergiovanni, School Management - Theoretical and Practical Aspects, Tel Aviv 2002.

${ }_{23}$ Active and involved learning based on projects and dilemmas is a method of learning that has developed also in the Gordon College of Education adjusted to the learner and life in the $21^{\text {st }}$ century. It inspires the intrinsic motivation to learn, to develop, and to contribute to society and to the environment (Gordon College of Education, PBL - Active and Involved Learning, n.d.).

${ }^{24}$ A. Peled, G. Ner, Initiative Thinking, Jerusalem 1999. 


\section{Research Participants}

About 33 parents from 6 preschools where there were no significant initiatives and about 33 parents from 6 preschools with the Academia Classroom program where there were significant initiatives participated in the research study. The preschools are state preschools in the Jewish sector. The division between the parents of the children who attend the younger class and the parents of the children who attend the older class in the preschool is almost equal. In addition, most of the parents have an academic education, 86.4\%, and most of them, $77.3 \%$, define their socioeconomic situation as moderate, $18.2 \%$ as high, and only $3 \%$ as low. Most of the respondents are women, $83.3 \%$. The questionnaires were distributed to the parents by the preschool teachers.

\section{Research Instruments}

The data were collected using a structured questionnaire taken from the research study of Gilat, Rosso Zimet, Claudy, and Tabak. ${ }^{25}$ The questionnaire was adjusted to this research study and questions were added pertaining to the existence of educational initiative in the preschool. Then the questionnaire was given to five instructors who are staff member in the early childhood education department (experts in the field) to examine its feasibility and suitability to the research question. The structure of the questionnaire is: (1) the characteristics of the responding parents, (2) the social and professional status of the preschool teacher in society, and (3) satisfaction with the functioning of the preschool teacher in different areas of her work in the preschool. ${ }^{26}$

\section{Research Process}

The questionnaires were distributed through the preschool teachers via the Internet in January 2019. Half were given to the parents in preschools participating in the program and half were given to the parents in preschools not participating in the program.

\footnotetext{
${ }^{25}$ Y. Gilat et al., Perception of Parents regarding.

${ }^{26}$ Ibidem.
} 


\section{Findings}

\section{Research Variables}

Table 1

Research Variables: Mean, Standard Deviation, Reliability, and (Pearson) Correlation Coefficient

\begin{tabular}{|l|c|c|c|c|c|c|}
\hline & Mean & $\begin{array}{c}\text { Standard } \\
\text { Deviation }\end{array}$ & Min & Max & $\begin{array}{c}\text { Reliabili- } \\
\text { ty (Cron- } \\
\text { bach's a) }\end{array}$ & $\begin{array}{c}\text { (Pearson) } \\
\text { Correlation } \\
\text { Coefficient }\end{array}$ \\
\hline $\begin{array}{l}\text { Preschool } \\
\text { Teacher } \\
\text { Image }\end{array}$ & 4.53 & 0.66 & 2.00 & 5.86 & 0.70 & \\
\hline $\begin{array}{l}\text { Satisfaction } \\
\text { with } \\
\begin{array}{l}\text { Preschool } \\
\text { Teacher }\end{array}\end{array}$ & 5.38 & 0.66 & 3.25 & 6.00 & 0.92 & $.348^{* *}$ \\
\hline
\end{tabular}

$\mathrm{p}<.01,{ }^{*} \mathrm{p}<.05$.

The two variables were measured through a scale of six values (1 low, 6 high) and good reliability ( $\alpha>=.70)$. The image of the preschool teacher is on a moderate-high level relative to the measurement scale. The satisfaction with the preschool teacher is on a high level (relative to the measurement scale). There is a positive correlation between the two measures $(r=.348, p<.01)$ that indicates a positive relationship between the two.

Table 2

Comparison of the Means of Satisfaction with the Preschool Teacher of the Parents of Children in the Preschools Where There Is a Program and in the Preschools Where There Is No Program

\begin{tabular}{|l|c|c|}
\hline \multirow{2}{*}{} & \multicolumn{2}{|c|}{$\begin{array}{c}\text { Preschool Participates in } \\
\text { Peer Academia Program }\end{array}$} \\
\cline { 2 - 3 } & No & Yes \\
\hline Respondents & 31 & 29 \\
\hline Transmission of learning contents & 5.65 & 5.72 \\
\hline Initiatives and significant projects in the preschool & 3.24 a & $5^{\text {a }}{ }^{\text {a }}$ \\
\hline $\begin{array}{l}\text { Involving the parents, informing them, and integrating } \\
\text { them in unique initiatives in the preschool }\end{array}$ & $3.25^{\mathrm{b}}$ & $5.66^{\mathrm{b}}$ \\
\hline Integration of technology in the learning in the preschool & $3.65^{\mathrm{c}}$ & $5.14^{\mathrm{c}}$ \\
\hline $\begin{array}{l}\text { Organization of the learning environments by the pre- } \\
\text { school teacher }\end{array}$ & 5.58 & 5.59 \\
\hline
\end{tabular}




\begin{tabular}{|l|c|c|}
\hline $\begin{array}{l}\text { Involvement of the children in the construction of the edu- } \\
\text { cational environment }\end{array}$ & $3.72^{\mathrm{d}}$ & $5.55^{\mathrm{d}}$ \\
\hline Quality of the teaching of the preschool staff & 5.48 & 5.55 \\
\hline Preschool library and reading quality books to the children & 5.19 & 5.38 \\
\hline $\begin{array}{l}\text { Preschool teacher's involvement in the activity in the pre- } \\
\text { school yard }\end{array}$ & 5.32 & 5.48 \\
\hline Celebrations in the preschool & 5.61 & 5.52 \\
\hline Relationship with the parents & 5.13 & 5.48 \\
\hline Identification of special needs of children & 5.42 & 5.24 \\
\hline Practices of hygiene and cleanliness & 5.35 & 5.45 \\
\hline Education for a healthy lifestyle in the preschool & 5.58 & 5.69 \\
\hline Solving conflicts among children & 5.35 & 5.41 \\
\hline Parents' meetings & 5.23 & 5.41 \\
\hline Satisfaction with the preschool teacher & 5.25 & 5.51 \\
\hline
\end{tabular}

$\mathrm{a}, \mathrm{b}, \mathrm{c}, \mathrm{d}$ The difference between the groups is significant $(\mathrm{p}<.05)$ after the adjustments to multiple comparison (Bonferronni).

\section{Implications}

The comparison of the perception of the image of the preschool teachers did not indicate differences between parents in the preschools where there were educational initiatives and the preschools where such initiatives did not exist. A difference in the satisfaction with the preschool teacher was not found between the pre-kindergarten and the kindergarten. However, it was found significantly that in the preschools where there are educational initiatives the parents are satisfied with the existence of initiatives and projects in preschool. Similarly, it was found that in the preschools where there are educational initiatives the parents are more satisfied with the integration of technology in the learning in the preschool, and similarly prominent satisfaction was found also with the involvement of the children in the building of the educational environment.

\section{Discussion}

The population of this research gives insight into the preschool teacher's image. Most of the respondents are women, apparently because of the interaction that preschool teachers tend to create more with the mothers. The qu- 
estion of gender arises in the context of its impact on the profession's image. About $99.2 \%$ of the preschool managers in state education are women. ${ }^{27}$ This question causes thinking about parents' involvement and the creation of the interaction between preschool teachers and fathers and about the training of men for the profession of preschool teacher. These are issues pertaining to the prestige of the profession and the question of the conditions and the salary that impact the status of the profession. ${ }^{28}$

Another way to attempt to understand the gap about the preschool teacher's low image is to listen to the public resonance expressed in the public conversation about preschools and preschool teachers and in the media. There are many negative articles published often in the local and national media about preschool teachers. To create a change in the image, it is necessary to cause broad positive resonance in the public, and for this purpose it is possible to recruit the educational initiatives. The significant findings about parents' satisfaction with the initiatives in the Academia Classroom preschools reinforce this. These can constitute an engine for positive advertisement of the activity. the significant findings about, the integration of technology in the preschool, and the involvement of the children in the building of the environment in the program prove that the parents are aware of what is done in the program.

It is possible to learn that the many efforts dedicated in the training college to the students in the topic of technology processes are bearing fruit. The integration of technology contributed to parents' satisfaction. This finding counters the conservative perceptions of the parents who tend to object to the integration of technological means in the preschool and in the school since they do not understand the benefit. ${ }^{29}$ As described in the professional literature, the increase of the involvement and explanation, with illustration, is helpful; namely, the parents realized that iPads were used for learning and a meaningful tool of learning. The initiatives in preschools enable display of high skills and integration of innovative pedagogy, tailored to the spirit of the Ministry of Education. ${ }^{30}$

In addition, it is possible to learn and to conclude that to influence the preschool teacher's image it is necessary to go out from within the walls of

${ }^{27}$ Central Bureau of Statistics, Table 2: Teaching Workers in Preschool Education according to Supervision and Select Traits, Tables, Figures, and Maps, Central Bureau of Statistics, Israel 2019. Retrieved from: https://www.cbs.gov.il

${ }^{28}$ M. Ben Peretz, Status of the Teacher, New Directions, Position Paper, Haifa 2009; M. Cochran-Smith, Constructing Outcomes in Teacher Education; L. Darling-Hammond, Teaching for America's Future, p. 162-183.

${ }^{29}$ E. Salant, Inhibitory Factors in Computerized Reforms, Parental Objections, Mofet 2016.

${ }^{30}$ Department of Preschool Education, Thoughts about the Future Preschool. Ministry of Education, Pedagogical Administration, 2018, Retrieved from: http://edu.gov.il/minhalpedagogy/preschool/subjects/guides-teacher/Pages/ganatidi.aspx 
the preschool into the community, but first it is necessary to cultivate the preschool teachers' awareness of this issue. ${ }^{31}$ Torin $^{32}$ addressed the image and stereotype of the teacher in the Israeli media and reached the conclusion that the teachers' image is mocked and negative.

The conclusions of research studies engaged in the influence of the media on the teacher's image in society. Hargreaves et al..$^{33}$ indicate that the school must create relationships with the local media. In England a significant change was performed in favor of the teacher's image in the media. Hence, the awareness of the branding of the preschool and the documentation and publicization of the educational initiatives may contribute to the improvement of the preschool teacher's professional image in society. This topic requires clarification and learning about how to use the era of the social networks, and how to integrate tools in the training of the students and the preschool teachers on this topic.

\section{Conclusion}

There are significant gaps in the findings between the preschools participating in the program and the preschools not participating, thus indicating the contribution of the program in general and initiatives in particular to the parents' satisfaction. It is possible to learn from these findings that the educational initiatives have impact and that this is an optimal way to create relationships with the children's home. The findings and the review of the literature indicate the need to advertise in the public.

\section{Research Limitations}

The research study did not address the parents of children from a low socioeconomic status, when it is reasonable that there the level of involvement is lower. The research study did not examine the feasibility of educational initiatives in the preschool in different environments and in every preschool. When there are no student teachers in the preschool. In addition, the program has many resources that do not exist in every preschool.

${ }^{31}$ T. Levin, Y. Nevo, The Future Elementary School as a Life Reality. In: The Contemporary School, From a Complex Existence to a Challenging Future: A Reader, Ministry of Education, Culture, and Sport, 1997.

32 A. Torin, Representations of Teachers in Israeli Media, Raanana 2014.

${ }^{33}$ L. Hargreaves et al., The Status of Teachers and the Teaching Profession in England: Views from inside and outside the Profession, Cambridge 2007. 


\section{BIBLIOGRAPHY}

Aharonov R., Haviv-Nadan D., Education for Initiative, 2015, Retrieved from the website of Department A for Elementary Education, September 10, 2016: http://cms.education. gov.il/EducationCMS/Units/Yesodi/Hevra/yazamut/Maamar1.htm

Ben Peretz M., Status of the Teacher, New Directions, Position Paper, Haifa University, 2009.

Ben-Alia N., Citizenship of Education in Israel: Deregulation, Democratization, and Increased Responsibility. Jerusalem: Hebrew University, Floersheimer Institute for Policy Studies, 2010.

Blass N., Review of the Literature and Description of a Case on the Topic of the Improvement of the Attractiveness of the Teaching Profession. Submitted to the Initiative for Applied Research in Education, Staff of Experts for the Activity "Who Will Teach When Teachers Are Lacking?", Ministry of Education, Israel 2009.

Brandt R., Powerful Learning, Association for Supervision and Curriculum Development, 1998.

Bronfenbrenner U., Ecology of the Family as a Context for Human Development: Research Perspectives, Development Psychology, 1986, 22.

Central Bureau of Statistics, Table 2: Teaching Workers in Preschool Education according to Supervision and Select Traits, Tables, Figures, and Maps, Central Bureau of Statistics, Israel, 2019. Retrieved from: https://www.cbs.gov.il

Chall J.S., The Academic Challenge: What Really Works in the Classroom? Gilford, New York 2000.

Cochran-Smith M., Constructing Outcomes in Teacher Education: Policy, Practice and Pitfalls, Educational Policy Analysis Archives, 2001, 9(11).

Darling-Hammond L., Teaching for America's Future: National Commissions and Vested Interests in an Almost Profession, Educational Policy, 2000, 14(1).

Department of Preschool Education, Thoughts about the Future Preschool, Ministry of Education, Pedagogical Administration, 2018, Retrieved from: http://edu.gov.il/minhalpedagogy/preschool/subjects/guides-teacher/Pages/ganatidi.aspx

Department of Research and Development, Experiments and Initiatives 2019, Future Oriented Pedagogy. Ministry of Education. Retrieved from the website: http://edu.gov.il/ minhalpedagogy/mop/pedagogy-disign/Pages/future-pedagogy.aspx

Elizur Y., Involvement, Partnership, and Empowerment: A Comparative Model for the Development of a Work Alliance with Families, Conversations: Israeli Journal for Psychotherapy, 1996, 10(2).

Fisherman S., Professional Identity and Burnout among Teaching Workers, Shanan Press, Haifa 2016.

Gibbons M., The Self-Directed Learning Handbook: Challenging Adolescent Students to Excel, San Francisco CA 2002.

Gilat Y., Rosso Zimet G., Claudy T., Tabac E., Perception of Parents regarding the Status and Functioning of the Preschool Teacher, Researchers @ Early Childhood, 5. Levinsky College of Education, 2018.

Gordon College of Education, PBL - Active and Involved Learning. Retrieved on February 18, 2019 from: https:/ / www.gordon.ac.il

Gordon College of Education, The Peer Academia Program. Retrieved on February 18, 2019 from: https://www.gordon.ac.il

Hargreaves L., Cunningham M., Hansen A., Mclntyre D., Oliver C., Pell T., The Status of Teachers and the Teaching Profession in England: Views from inside and outside the Profession, Final Report of the Teacher Status Project, University of Cambridge, Cambridge 2007. 
Hoyle E., Teaching: Prestige, Status, and Esteem, Educational Management \& Administration, 2001, 29(2).

Levin T., Nevo Y., The Future Elementary School as a Life Reality, [In:] The Contemporary School, From a Complex Existence to a Challenging Future: A Reader, Ministry of Education, Culture, and Sport, 1997.

Magan D., Planning Aspects of Personnel in Teaching and Training for Teaching, Central Bureau of Statistics, Israel 2015.

McKinsey Report, How the World's Best-Performing School Systems Come Out on Top, 2007. http://www.mckinsey. com/clientservice/socialsector/resources/pdf/ Worlds_School_systems_final.pdf

Peled A., Initiative Thinking, Branco Weiss Institute for the Cultivation of Thinking and the Department of Curricula, Ministry of Education, Jerusalem 1996.

Peled A., Ner G., Initiative Thinking, Branco Weiss Institute for the Cultivation of Thinking, Ministry of Education, Jerusalem 1999.

Pessig D., Taxonomy of Skills and Future Abilities, [In:] The Contemporary School, From a Complex Existence to a Challenging Future: A Reader, Ministry of Education, Culture, and Sport, 1997.

Salant E., Inhibitory Factors in Computerized Reforms, Parental Objections, Mofet Institute, 2016.

Sergiovanni T., School Management - Theoretical and Practical Aspects, The Open University, Tel Aviv 2002.

Torin A., Representations of Teachers in Israeli Media, Mofet Institute, Raanana 2014.

Trachtenberg M., Report of the Committee for Social Economic Change, Jerusalem 2011.

Zimmerman B.J., Barry Zimmerman Discusses Self-Regulated Learning Processes, Emerging Research Commentary, 2011. 